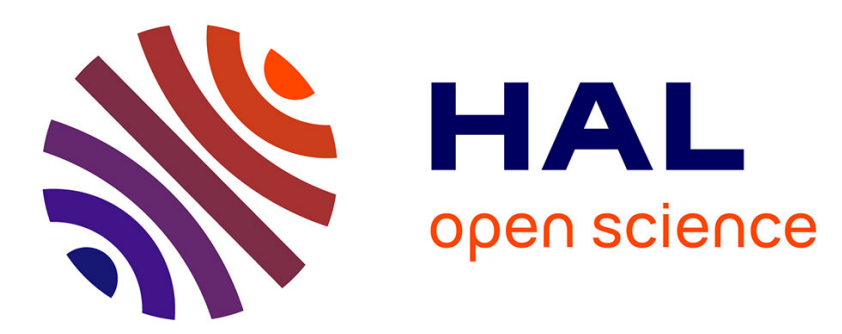

\title{
PARITY NON-CONSERVING ASYMMETRY OF LONGITUDINALLY POLARIZED THERMAL NEUTRONS PROPAGATION
}

\author{
L. Bondarenko, S. Zhukov, V. Kuznetsov, Yu. Mostovoy, A. Beda, B. \\ Vodennikov, G. Danilyan, V. Dronyaev, V. Kutsenko, V. Novitskii, et al.
}

\section{To cite this version:}

L. Bondarenko, S. Zhukov, V. Kuznetsov, Yu. Mostovoy, A. Beda, et al.. PARITY NON-CONSERVING ASYMMETRY OF LONGITUDINALLY POLARIZED THERMAL NEUTRONS PROPAGATION. Journal de Physique Colloques, 1984, 45 (C3), pp.C3-81-C3-83. 10.1051/jphyscol:1984316 . jpa-00224030

\section{HAL Id: jpa-00224030 https://hal.science/jpa-00224030}

Submitted on 1 Jan 1984

HAL is a multi-disciplinary open access archive for the deposit and dissemination of scientific research documents, whether they are published or not. The documents may come from teaching and research institutions in France or abroad, or from public or private research centers.
L'archive ouverte pluridisciplinaire HAL, est destinée au dépôt et à la diffusion de documents scientifiques de niveau recherche, publiés ou non, émanant des établissements d'enseignement et de recherche français ou étrangers, des laboratoires publics ou privés. 


\title{
PARITY NON-CONSERVING ASYMMETRY OF LONGITUDINALLY POLARIZED THERMAL NEUTRONS PROPAGATION
}

\author{
L.N. Bondarenko, S.V. Zhukov, V.L. Kuznetsov, Yu.A. Mostovoy, A.G. Beda”,

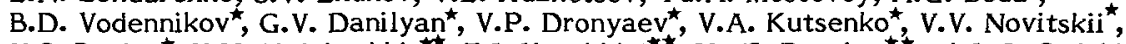 \\ V.S. Pavlov ${ }^{\star}$, V.M. Kolobashkin ${ }^{\star}$, E.I. Korobkina* ${ }^{\star}$, Yu.F. Pevchev ${ }^{\star}$ and A.G. Sadchikov ${ }^{\star \star}$ \\ Kurchatov Atomic Energy Institute, U1. Kurchatova 46, M oscow 123182 , U.S.S.R. \\ Institute of Theoretical and Experimental Physics, B. Cherem ushkinskaya U1. 89, \\ Moscow 117 253, U.S.S.R. \\ ${ }^{\star}$ M oscow Engineering-Physical Institute, MosCow, U.S.S.R. \\ Résumé - L'asymétrie ne conservant pas la parité dans la propagation de \\ neutrons thermiques polarisés longitudinalement a été mesurée pour quelques \\ éléments. Les valeurs suivantes concernant la différence relative des sec- \\ tions efficaces totales pour des neutrons d'hẻlicités opposées (unités $10^{-6}$ ) \\ ont êté obtenues : uranium - $233: 0,9 \pm 0,9$, plomb 207: $0,9 \pm 1,7$, plomb \\ naturel : $0,0 \pm 0,6$, thorium $-232: 0,7 \pm 2,3$, zirconium nature $1: 0,5 \pm 0,9$, \\ brome naturel : $11,4 \pm 1,4$. \\ Abstract - The parity-non-conserving (PNC) asymmetry of the longitudinally \\ polarized thermal neutron propagation was measured for some elements. The \\ following values (in units of $10^{-6}$ ) for the relative difference in total \\ cross-sections for neutrons of opposite helicities have been obtained : \\ uranium - $233: 0.9 \pm 0.9$, lead - $207: 0.9 \pm 1.7$, natura1 1ead : $0.0 \pm 0.6$, \\ thorium $-232: 0.7 \pm 2.3$, natural zirconium $: 0.5 \pm 0.9$ and natural \\ bromine : $11.4 \pm 1.4$.
}

The investigation of parity-non-conserving effects aims to a better knowledge of the nucleon weak interaction structure. It requires a profound understanding of both the complex excited nuclear states and probably the nuclear fission mechanism.

In our opinion, it is necessary to collect further experimental data over a wide range of effects and for a larger number of nuclei.

Our previous work / $/$ / was devoted to measuring the relative difference in the total. cross-sections of uranium - 233 for thermal neutrons with opposite helicities :

$$
P=\left(\sigma_{+}-\sigma_{-}\right) /\left(\sigma_{+}+\sigma_{-}\right)
$$

This was of interest in connection with the discovery by G.V. Val'skii et al. /2/ of a sign change in the PNC asymmetry of fragment emission from ${ }^{23} 3 \mathrm{U}$ fission occurring for $0.17 \mathrm{eV}$ neutrons. Indeed, this feature indicates that there is at this energy a neutron resonance and, within the assumption that it is a p-wave resonance, theory predicts $\mathrm{P}=5 \times 10^{-5} / 3,4 /$.

A zero result was obtained /1,5/ which stimulated O.P. Sushkov and V.V. Flambaum /6/ to produce a new estimate of $\mathrm{P}=(1-2) \times 10^{-6}$ based on some additional assumptions about the parameters of the compound nucleus.

We have now carried out a further search for PNC asymmetries in thermal neutron propagation with the facilities described in /1/. The results obtained for a number of nuclei are presented here. 
The target was placed in front of a neutron detector in a polarized thermal neutron beam with a longitudinally directed magnetic field. The sign of neutron polarization was reversed by means of a "spin-flipper" i.e. a bending electromagnet and a current-sheet $/ 7 /$. The experimental asymmetry was calculated from the difference in detector readings with opposite neutron helicities.

A compensation method was used to cancel the effect of any false asymmetry due to instabilities in the intensity of the incident neutron beam. A special monitor detector was placed in part of the neutron beam by-passing the target, and the difference between the monitor and main detector currents was measured. Thus the influence of any instability in the intensity of the incident neutron beam was reduced in the ratio of this compensated current to the main detector current. As a result, this type of false asymmetry was suppressed by a factor of $100-1000$. Since the detector and monitor were connected to the same load impedance, instabilities in both the impedance and the measuring instrument were also suppressed to a considerable extent.

The spin-guiding magnetic field at the target was also reversed periodically to counter any possible asymmetry in the apparatus.

The neutron detectors, consisting of assemblies of ${ }^{3} \mathrm{He}$ counters of the SNM - 16 and SNM - 17 types, were operated under ionization chamber conditions. The tota1 intensity of the polarized neutron beam was $\simeq 5 \times 10^{7} \mathrm{n} / \mathrm{sec}$ with a degree of polarization of $(74 \pm 0.5) \%$ and the polarization was reversed with a frequency of $1 \mathrm{~Hz}$. The measurements were made automatically by means of a high stability digital voltmeter controlled on-1ine by an Electronika - 60 computer. The work was carried out at the IR-8 reactor of the I.V. Kurtchatov Atomic Energy Institute.

Table I presents the results obtained. No PNC asymmetry in the propagation of thermal, longitudinally polarized, neutrons for newly investigated nuclei was observed within the current accuracy of the experiments.

TABLE I

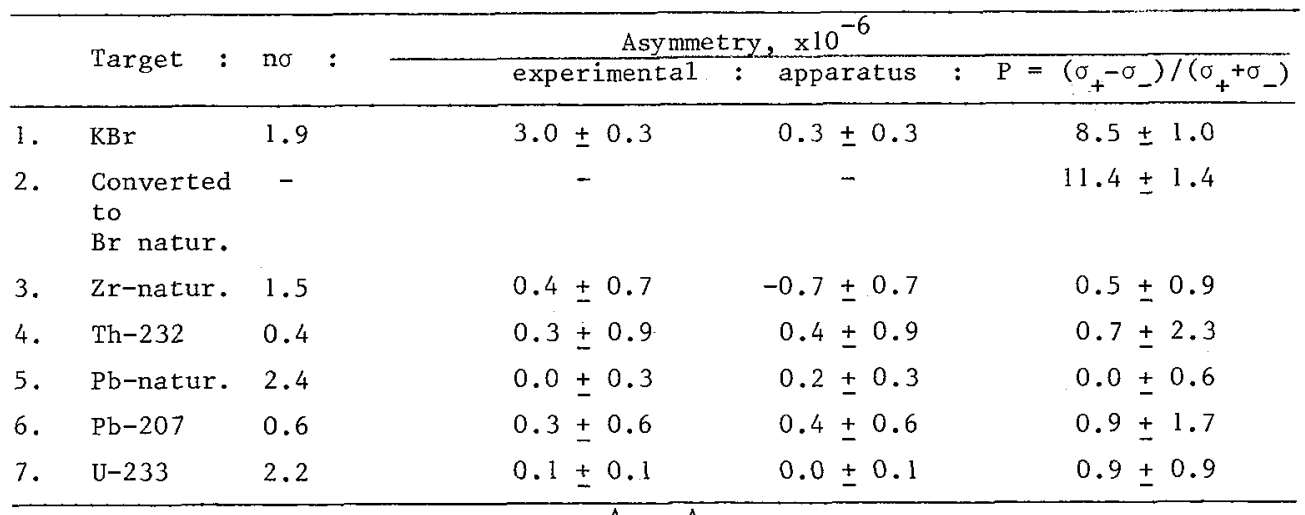

Note : The apparatus asymmetry $A_{a p p}=A_{+}-A_{-}$, where $A_{ \pm}$are the experimental asymmetry values obtained for opposite directions of the guiding magnetic field.

\section{ACKNOWLEDGEMENTS}

The authors would like to thank S.T. Belyaev for his interest in this work and for his encouragement, V.F. Apalin and A.N. Martemyanov for electronic equipment, O.P. Sushkov, V.V. Flambaum, D.F. Zaretskii and V.K. Sirotkin for useful discussions, and the IR-8 reactor team for their help with this work. 


\section{REFERENCES}

1. BONDARENKO L.N. et al. JETP Lett., 1983, v.38, p. 141 (in Russian)

2. VAL'SKII G.V. et a1., Preprints LINP 796 and 797 (1982), issued by Leningrad Institute of Nuclear Physics (in Russian)

3. BUNAKOV V.E. and GUDKOV V.P. Preprints LINP nn 661 (1981), 763 ( 1982$)$, issued ibid. (in Russian)

4. SUSHKOV O.P. and FLAMBAUM V.V., Uspekhi Fiz. Nauk, 1982, v.136, p. 3 (in Russian)

5. VESNA V.A. et a1. JETP Lett., 1983, v. 37, p. 410 (in Russian)

6. SUSHKOV O.P. and FLAMBAUM V.V. Preprint INP 83-31, issued by Novosibirskii Institute of Nuclear Physics (1983), (in Russian)

7. MOSTOVOY Yu.A., Pribory i Tekhnika Experimenta, 1982, n. 3, p. 24 (in Russian)

8. HECKEL et al., Ph. Lett. v. 119B, p. 298, 1982. 